\title{
Performance of hydromagnetic squeeze film in longitudinally rough conducting truncated conical plates
}

\author{
J. V. Adeshara ${ }^{1}$, M. B. Prajapati ${ }^{2}$, G. M. Deheri ${ }^{3}$, and R. M. Patel ${ }^{4}$ \\ 1. Research Scholar, Department of Mathematics, H. N. G. University, Patan-384 265, Gujarat State, India. \\ Email: adesharajatin01@gmail.com \\ 2. Head, Department of Mathematics, H. N. G. University, Patan - 384 265, Gujarat State, India. \\ 3. Department of Mathematics, S. P. University, Vallabh Vidyanagar - 388 120, Gujarat State, India. \\ 4. Department of Mathematics, Gujarat Arts and Science College, Ahmedabad - 380006 Gujarat State, India. * \\ Corresponding author: rmpatel2711@gmail.com
}

Abstract-An attempt was made to study and analyze a hydromagnetic squeeze film's behavior between longitudinally rough conical truncated plates. A transverse magnetic field is applied. The associated equation of Reynolds is solved by investigating the behavior of performance characteristics with appropriate boundary conditions. The results show that the bearing system performance is improved vis - à - vis a bearing system that works with a conventional lubricant. The results show that longitudinal roughness in comparison with transverse roughness is more helpful. This article reveals that the negative effect induced by standard deviation can be overcome completely by the positive effect of magnetization parameter and conductivities by choosing suitable aspect ratio and semi-vertical angle in the case negative skewed roughness.

Index Terms- Truncated Conical plates, squeeze film, longitudinal roughness, conductivity, load bearing capacity.

\section{INTRODUCTION}

A number of theoretical and experimental analyzes on the hydromagnetic lubrication of plane metal bearings (Elco-Huges [8], Kuzma [11],Kuzma et al. [12], Dodge et al[7]). Shukla [18] dealt with the hydromagnetic squeeze film bearing for conducting lubricants between non conducting non-porous surfaces in the presence of a transverse magnetic field. Shukla -Prasad [19]. The performance of a hydromagnetic squeeze film between non - porous surfaces was discussed and the effect of surface conductivity on the performance of the bearing system was studied. Sinha -Gupta [20] investigated the hydromagnetic effect of annular plates on porous squeeze films. Patel - Hingu[14] investigated this effect of squeezing films between circular disks. PatelGupta [13] used Morgan Cameron approximation and simplified this analysis to carry out hydromagnetic squeeze films between parallel plates with different geometric shapes. For squeeze films between porous plates, Prakash-Vij [17] investigated the load carrying capacity and time height relationship. In this article, several geometries were incorporated, such as circular, annular, elliptical, rectangular, conical and truncated conical plates. The performance of a hydromagnetic squeeze film between two porous conical plates was considered by Prajapati[16]. The study of magnetic fluid - based squeeze film behavior between porous conical plates was presented by Patel Deheri[15]. It was concluded here that the magnetic fluid and the cone's semi - vertical angle played key roles to enhance the bearing system performance.

Tzeng and Saibel[23] documented the random character of the roughness and presented stochastic concepts and managed to analyze a two dimensional inclined slider bearing with one dimensional roughness in the transverse direction to the sliding direction. Many researchers studied the effect of surface roughness (Davies[6],Tonder[22], Christensen- Tonder[3,4,5], Berthe - Godet[2] established and modified the Tzeng and Saibel approach[23] and proposed a comprehensive general analysis for both transverse and longitudinal roughness of the surface. The approach of Christenesen and Tonder was the basis for the study of the effect of surface roughness in a number of investigations (Ting [21], Guha[9], Gupta and Deheri[10], Andharia, Gupta and Deheri[1]).

Vadher et al [24] have recently studied and analyzed the hydromagnetic squeeze film behavior between conducting porous transversely rough triangular plates and it has been established that the negative effect of porosity and roughness could be neutralized to some extent by the positive effect of hydromagnetization in the case of negative skewed roughness.

The longitudinal roughness pattern was subjected to investigation in Andharia and Deheri [25, $26,27]$. Transverse roughness pattern in the presence of a magnetic fluid has been the matter of investigation in Lin et. al. [28]. 


\section{Available online at www.ijrat.org}

\section{ANALYSIS}

The configuration of the bearing system is given below

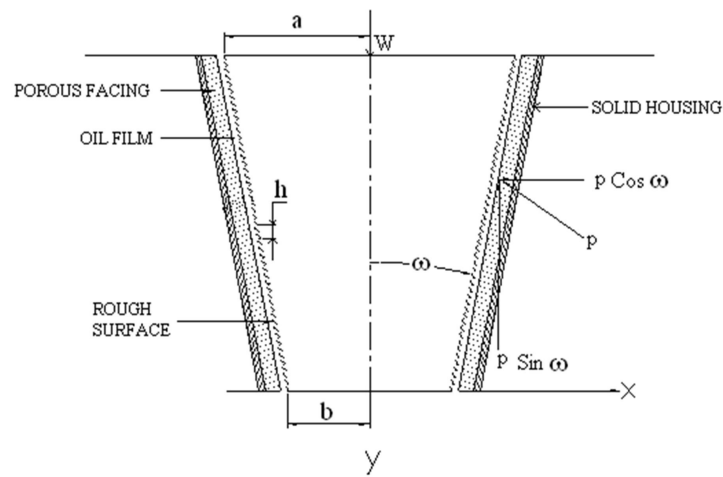

FIG. I. CONFIGURATION OF THE BEARING SYSTEM

It is assumed that the lower plate with a porous face is fixed while the upper plate moves along the normal to the lower plate. The plates are considered to be electrically conductive and a lubricant that conducts electrically fills the clearance space between them. Between the plates is applied a uniform transverse magnetic field. It is assumed that the bearing surfaces are transversely rough.

The flow in the porous medium satisfies the modified form of Darcy's law (Prajapati [16]) while in the film region the equations of hydromagnetic lubrication theory hold. Then, under the usual assumptions of hydromagnetic lubrication the modified Reynolds' equation for the lubricant film pressure (Prajapati [16], Prakash and Vij [17], Vadher et al [24]) is obtained as from equation $\left(\nabla^{2} p\right.$ insert equation no.)

$\frac{1}{x} \frac{d}{d x}\left(x \frac{d p}{d x}\right)=$

$\frac{\mathrm{h} \dot{\mu} \mathrm{A}}{\left[\frac{2}{\mathrm{M}^{3}}\left(\tanh \frac{\mathrm{M}}{2}-\frac{\mathrm{M}}{2}\right)\right]} \cdot \frac{1}{\left[\frac{\phi_{0}+\phi_{1}+1}{\left.\phi_{0}+\phi_{1}+\frac{\tanh (\mathrm{M} / 2)}{(\mathrm{M} / 2)}\right]}\right]}$

Where

$\mathrm{A}=$

$\mathrm{h}^{-3}\left[1-\alpha \mathrm{h}^{-1}+6 \mathrm{~h}^{-2}\left(\sigma^{2}+\alpha^{2}\right)-10 \mathrm{~h}^{-3}\left(\varepsilon+3 \sigma^{2} \alpha+\alpha^{3}\right)\right]$

Solution of this equation by making use of boundary conditions

$\mathrm{p}(\mathrm{a} \operatorname{cosec} \omega)=0 \quad ; \mathrm{p}(\mathrm{b} \operatorname{cosec} \omega)=$

Determines the distribution of pressure as

$$
\begin{gathered}
\mathrm{p}=\frac{-\bar{h}\left(a^{2}-b^{2}\right) \operatorname{cosec}^{2} \omega .}{4\left[\frac{2}{\mathrm{M}^{3}}\left(\tanh \frac{\mathrm{M}}{2}-\frac{\mathrm{M}}{2}\right)\right]} \cdot \\
\frac{\left[\frac{\ln (\mathrm{x} / \mathrm{b} \operatorname{cose} \omega)}{\ln (\mathrm{a} / \mathrm{b})}-\frac{(\mathrm{x} \sin \omega / \mathrm{b})^{2}-1}{(\mathrm{a} / \mathrm{b})^{2}-1}\right]}{\left[\frac{\phi_{0}+\phi_{1}+1}{\left.\phi_{0}+\phi_{1}+\frac{\tanh (\mathrm{M} / 2)}{(\mathrm{M} / 2)}\right]}\right.} \cdot B
\end{gathered}
$$

Where $\mathrm{B}=$

$\left[1-3 \alpha *+6\left(\sigma *^{2}+\alpha *^{2}\right)-10\left(\varepsilon *+3 \sigma *^{2} \alpha *+\alpha *^{3}\right)\right]$

The distribution of non - dimensional pressure is obtained

$$
\begin{gathered}
\mathrm{P}=\frac{-\mathrm{p} h^{3}}{\mu \dot{\mathrm{h}} \pi\left(a^{2}-b^{2}\right) \operatorname{cosec} \omega} \\
\operatorname{cosec} \omega \cdot\left[\frac{\ln (\mathrm{x} \sin \omega / \mathrm{b})}{\ln (\mathrm{a} / \mathrm{b})}-\frac{(\mathrm{x} \sin \omega / \mathrm{b})^{2}-1}{(\mathrm{a} / \mathrm{b})^{2}-1}\right] \mathrm{B} \\
\bullet \frac{4 \pi\left[\frac{2}{\left.\mathrm{M}^{3}\left(\tanh \frac{\mathrm{M}}{2}-\frac{\mathrm{M}}{2}\right)\right]}\right.}{\left[\frac{\phi_{0}+\phi_{1}+1}{\left.\phi_{0}+\phi_{1}+\frac{\tanh (\mathrm{M} / 2)}{(\mathrm{M} / 2)}\right]}\right.}
\end{gathered}
$$

Where in

$\mathrm{B}=$

$$
\begin{aligned}
& 1-3 \alpha^{*}+6\left(\sigma^{* 2}+\alpha^{* 2}\right)-10\left(\varepsilon^{*}+3 \sigma^{* 2} \alpha^{*}+\alpha^{* 3}\right) \\
& \text { Where } \sigma^{*}=\frac{\sigma}{\mathrm{h}}, \alpha^{*}=\frac{\alpha}{\mathrm{h}}, \quad \varepsilon^{*}=\frac{\varepsilon}{\mathrm{h}^{3}}
\end{aligned}
$$

Then the load carrying capacity given by

$$
\mathrm{w}=2 \pi \int_{\mathrm{b} \operatorname{cosec} \omega}^{\mathrm{a} \operatorname{cosec} \omega} \mathrm{p} \cdot \mathrm{xdx}
$$

is expressed in dimensional form as

$$
\mathrm{w}=\frac{-\mathrm{h} \pi\left(\mathrm{a}^{2}-\mathrm{b}^{2}\right) \operatorname{cosec} \mathrm{cos}^{4} \cdot\left[\left(\mathrm{a}^{2}+\mathrm{b}^{2}\right)-\frac{\left(\mathrm{a}^{2}-\mathrm{b}^{2}\right)}{\ln (\mathrm{a} / \mathrm{b})}\right] \mathrm{B}}{8\left[\frac{2}{\mathrm{M}^{3}}\left(\tanh \frac{\mathrm{M}}{2}-\frac{\mathrm{M}}{2}\right)\right]}
$$




\section{Available online at www.ijrat.org}

$$
\cdot \frac{1}{\left[\frac{\phi_{0}+\phi_{1}+1}{\phi_{0}+\phi_{1}+\frac{\tanh (\mathrm{M} / 2)}{(\mathrm{M} / 2)}}\right]}
$$

The load carrying capacity is obtained as dimensionless

$$
\begin{aligned}
& \mathrm{W}=-\frac{\mathrm{wh}^{3}}{\mu \mathrm{h} \pi^{2}\left(\mathrm{a}^{2}-\mathrm{b}^{2}\right)^{2} \operatorname{cosec}^{2} \omega} \\
& \mathrm{w}=\frac{\operatorname{cosec}^{2} \omega \cdot\left[\frac{(\mathrm{a} / \mathrm{b})^{2}+1}{(\mathrm{a} / \mathrm{b})^{2}-1}-\frac{1}{\ln (\mathrm{a} / \mathrm{b})}\right]}{8 \pi\left[\frac{2}{\mathrm{M}^{3}}\left(\tanh \frac{\mathrm{M}}{2}-\frac{\mathrm{M}}{2}\right)\right]} \\
& {\left[\frac{1}{\left.\phi_{0}+\phi_{1}+\frac{\tanh (\mathrm{M} / 2)}{(\mathrm{M} / 2)}\right]}\right.}
\end{aligned}
$$

Clearly, the distribution of pressure is determined by equation (3), while equation (4) gives the expression for the capacity of load carrying. These performance characteristics are dependent on different parameters such as $\mathrm{M}, \phi_{0}+\phi_{1}, \sigma^{*}, \alpha^{*}, \varepsilon^{*}, \mathrm{k}$ and $\omega$. These parameters describe the effect of the cone's magnetization, conductivity, standard deviation, variance, skewedness, aspect ratio and semi - vertical angle, respectively. This study reduces observation of Prakash and Vij [17]by setting the roughness parameters, magnetization parameters and conductivity parameters to be zero. Finally, considering the parameters of roughness as zero, this study results in the contributions of Shukla and Prasad [19], Dodge et al [7] and Sinha and Gupta [20] in special situations.

\section{Results and Discussion}

As the conductivity parameter $\phi_{0}+\phi_{1}$ increases, it can be easily noticed that the load carrying capacity increases for fixed values of $\mathrm{M}, \sigma^{*}, \alpha^{*}, \varepsilon^{*}, \mathrm{k}$ and $\omega$. Moreover, the effect of conductivity on the pressure distribution and load carrying capacity comes through the factor

$$
\left(\frac{\phi_{0}+\phi_{1}+\frac{\tanh (\mathrm{M} / 2)}{(\mathrm{M} / 2)}}{\phi_{0}+\phi_{1}+1}\right)
$$

This tends to as $\operatorname{tanhM} \sim 1,2$ / $\mathrm{M} \sim 0$ for large values of M. It is clear that these two functions increase the functionality $\phi_{0}+\phi_{1}$. From mathematical analysis, It can also be observed that the capacity of carrying pressure and load increases as $\phi_{0}+\phi_{1}$, somewhere else. An interesting point to be noted here is that the bearing with magnetic field can support a load even when there is no flow.

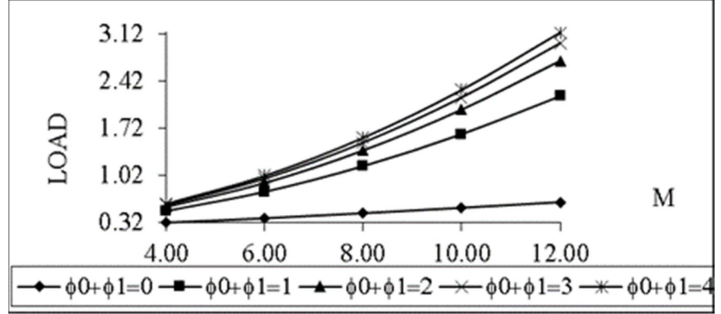

Figure 1: Variation of load carrying capacity with respect to $M$ and $\phi_{0}+\phi_{1}$

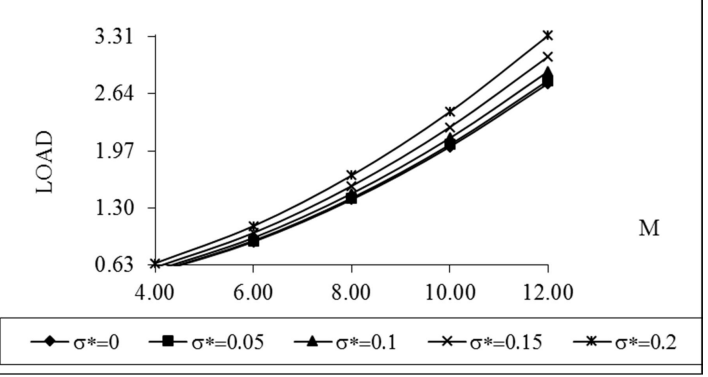

Figure 2: Distribution of load with respect to $M$ and $\sigma *$

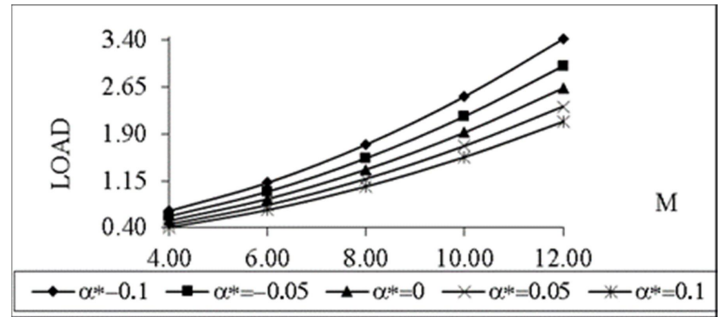

Figure 3: Profile of load bearing capacity with regards to $M$ and $\alpha^{*}$

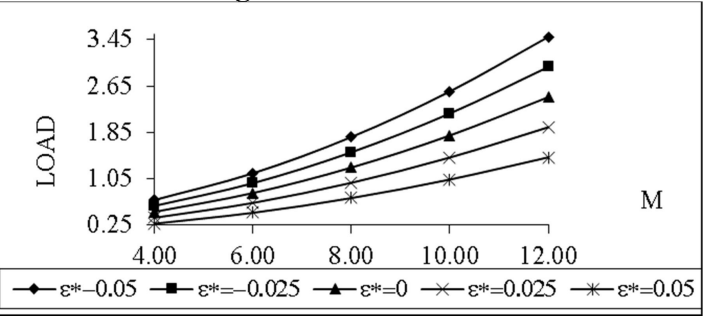

Figure 4: Variation of load carrying capacity with respect to $M$ and $\varepsilon^{*}$ 


\section{Available online at www.ijrat.org}

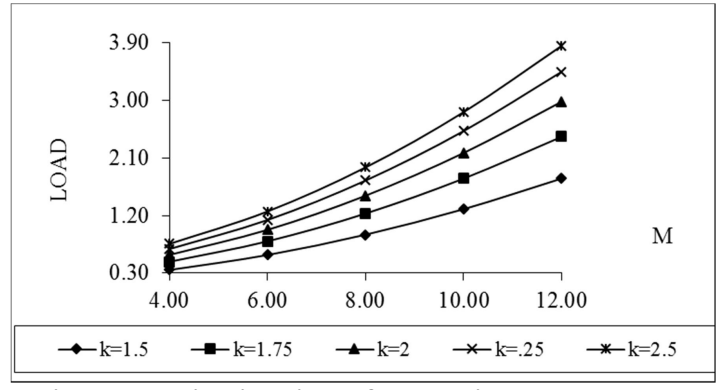

Figure 5: Distribution of load with respect to $M$ and $k$

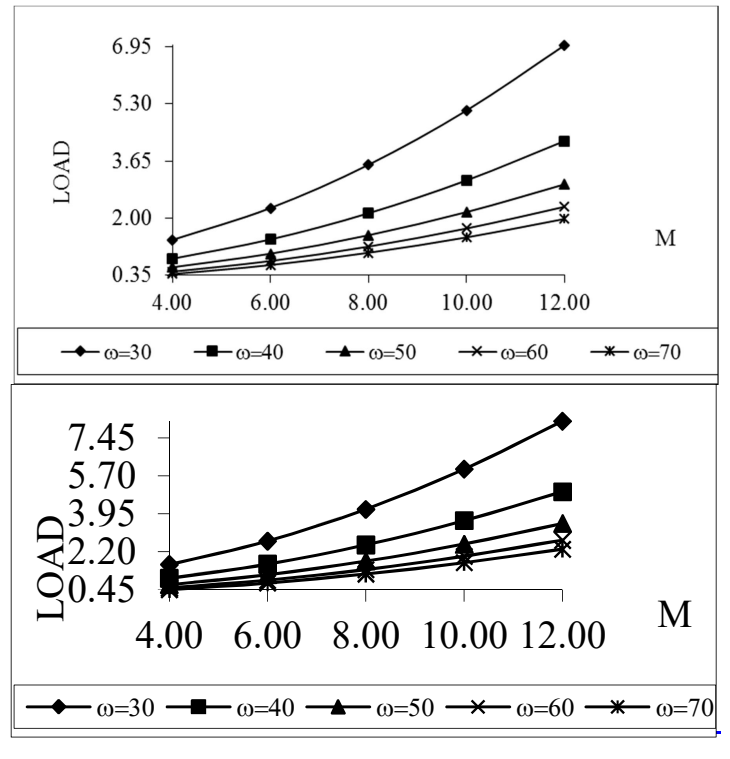

Figure 6: Distribution of load with respect to $M$ and $\omega$

The variation of the load carrying capacity with respect to the magnetization parameter is shown in Figures $(1-6)$ for different values of the conductivity parameter $\phi_{0}+\phi_{1}$,standard deviation $\sigma^{*}$; variance $\alpha^{*}$, skewness $\varepsilon^{*}$, aspect ratio $\mathrm{k}$ and semi - vertical angle respectively. From these figures it is clear that the load carrying capacity increases substantially with respect to the parameter of magnetization in which the effect of (-ve) all $\alpha^{*}$ is the most prevalent, followed by semivertical angle $\omega$. Furthermore, the standard deviation initially has a nearly negligible effect and the increase in load arrangement capacity for the combination of $\mathrm{M}$ and $\sigma *$ is relatively less compared to the other cases. In addition, the standard deviation effect is quite negative.

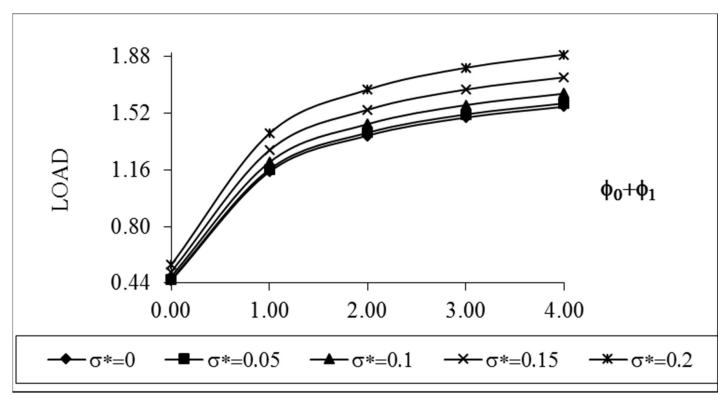

Figure 7: Profile of load bearing capacity with regards to $\phi_{0}+\phi_{1}$ and $\sigma *$

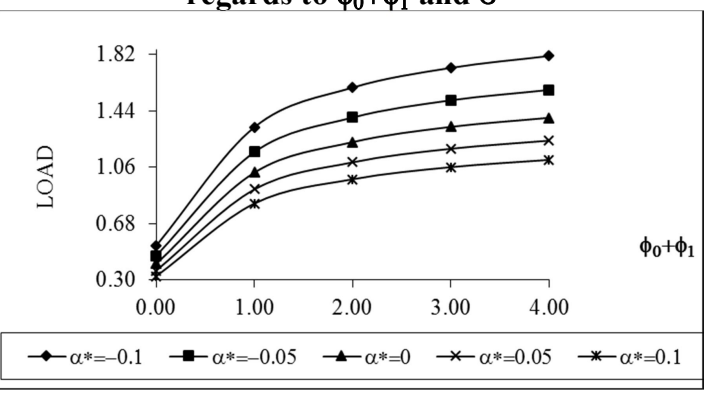

Figure 8: Variation of load carrying capacity with respect to $\phi_{0}+\phi_{1}$ and $\alpha^{*}$

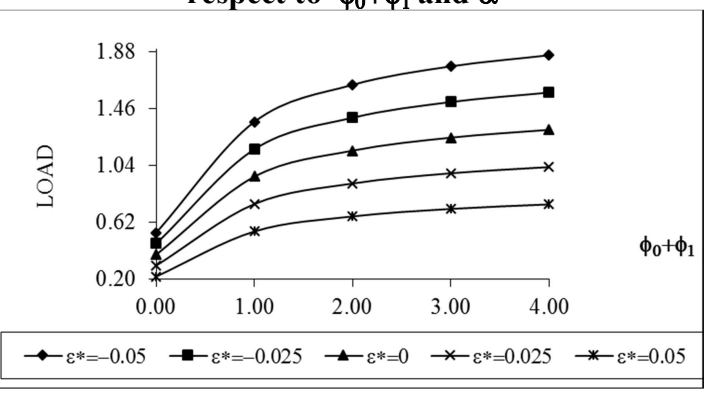

Figure 9: Distribution of load with respect to $\phi_{0}+\phi_{1}$ and $\varepsilon^{*}$

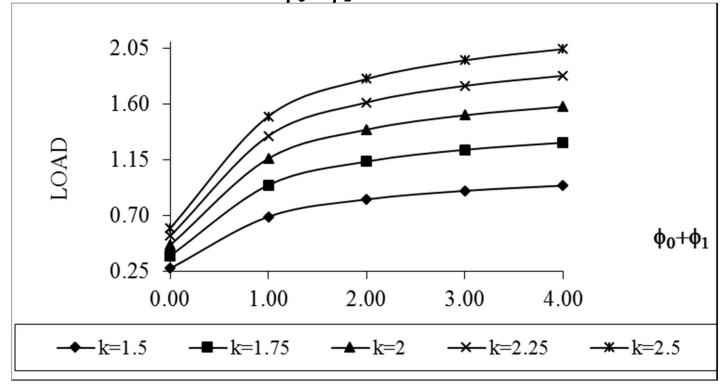

Figure 10: Profile of load bearing capacity with regards to $\phi_{0}+\phi_{1}$ and $\mathbf{k}$ 


\section{Available online at www.ijrat.org}

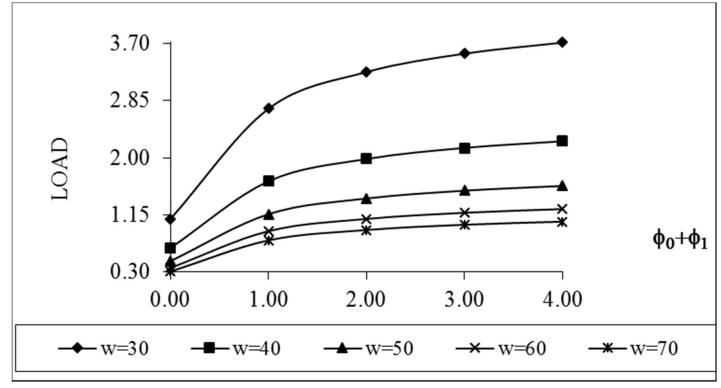

Figure 11: Profile of load bearing capacity with regards to $\phi_{0}+\phi_{1}$ and $\omega$

Figures (7 - 11) show the distribution of load carrying capacity with respect to conductivity $\phi_{0}+\phi_{1}$ for multiple parameter values $\sigma^{*}, \varepsilon^{*}, \alpha^{*}, \mathrm{k}$ and $\omega$ respectively. It is found that the conductivity tends to increase the capacity of the load carrying and the rate of increase in the initial stages is relatively higher. Here, the combined effect of the conductivity and aspect ratio is relatively better than the combined effect of conductivities, while the combined effect of negative $\varepsilon^{*}$ and conductivity $\phi_{0}+\phi_{1}$ is comparatively greater than the combined effect of negative $\alpha^{*}$ and conductivity $\phi_{0}+\phi_{1}$. Further, it is noted that the combined effect of conductivity and the aspect ratio lies between the effect of negative variance and skewness so far as the increase in load carrying capacity is concerned.

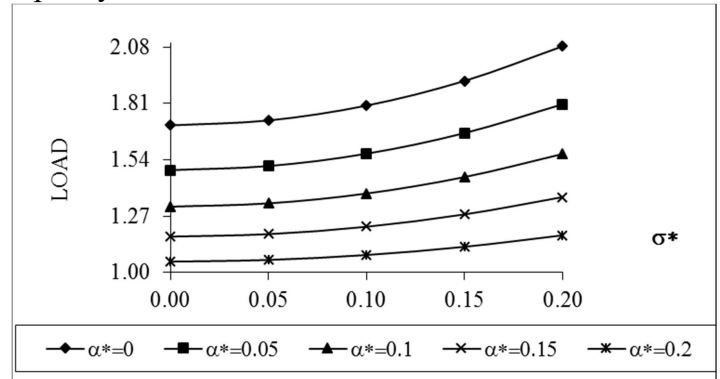

Figure 12: Variation of load carrying capacity with respect to $\sigma^{*}$ and $\alpha^{*}$

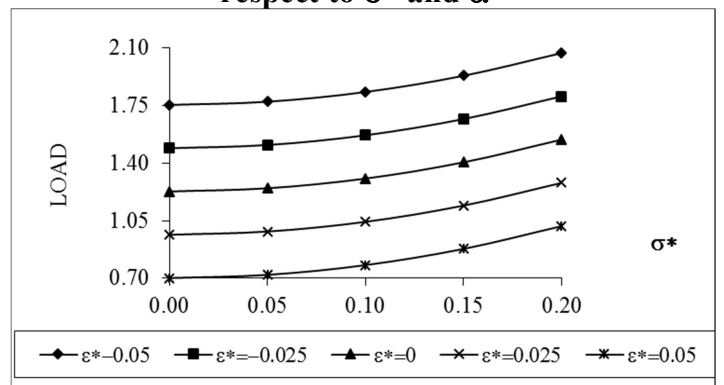

Figure 13: Distribution of load with respect to $\sigma^{*}$ and $\varepsilon^{*}$

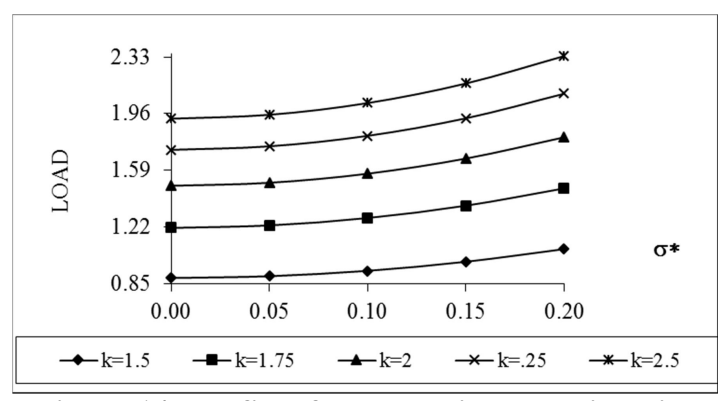

Figure 14: Profile of load bearing capacity with regards to $\sigma^{*}$ and $k$

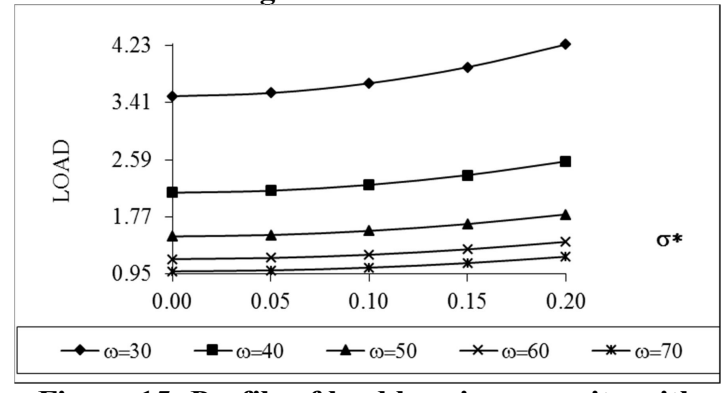

Figure 15: Profile of load bearing capacity with regards to $\sigma^{*}$ and $\omega$

Figures (12 - 15) provide the load carrying capacity distribution profile for the standard deviation associated with roughness for different variance, skew, aspect ratio and semi - vertical angle values.

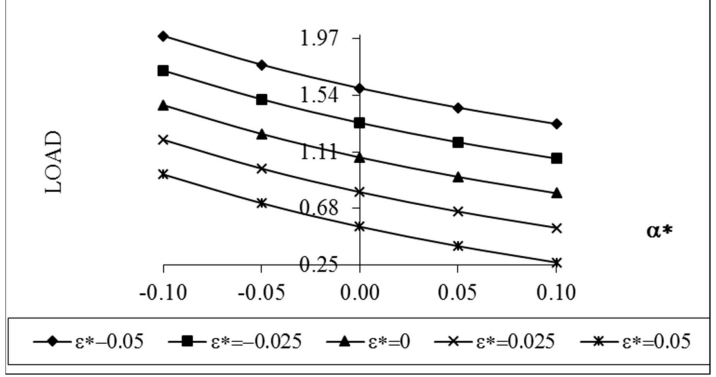

Figure 16: Variation of load carrying capacity with respect to $\alpha^{*}$ and $\varepsilon^{*}$

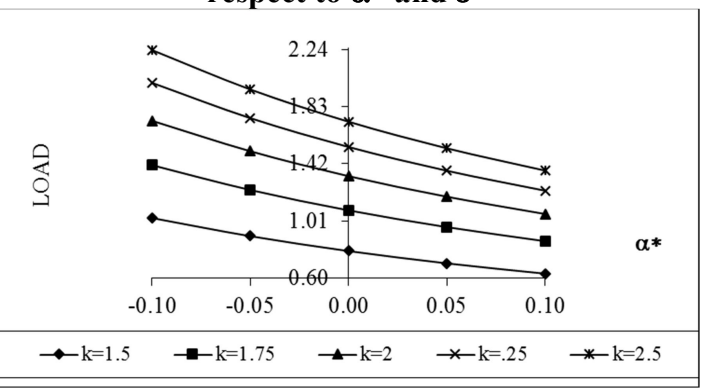

Figure 17: Distribution of load with respect to $\alpha^{*}$ and $k$ 


\section{Available online at www.ijrat.org}

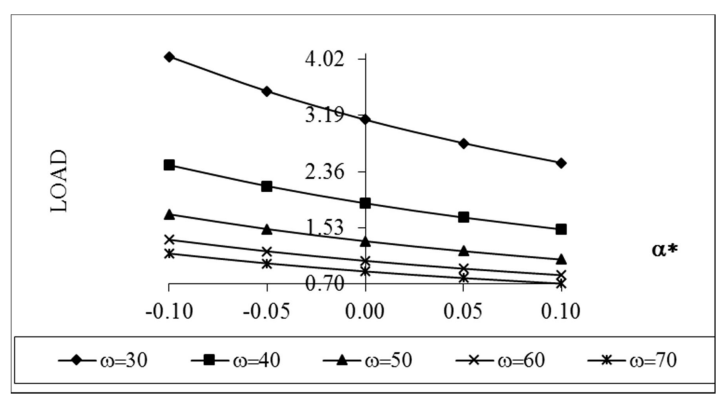

Figure 18: Distribution of load with respect to $\alpha^{*}$ and $\omega$

The rate of decrease is more pronounced in the case of skewness. Variation of load carrying capacity with respect to the variance for different values of skewness, aspect ratio and the semi vertical angle is presented in Figures (16-18) respectively. While $\alpha^{*}$ (+ve) increases the load carrying capacity, the (-ve) variance increases the load carrying capacity and this rate of increase is more in the case of the aspect ratio.

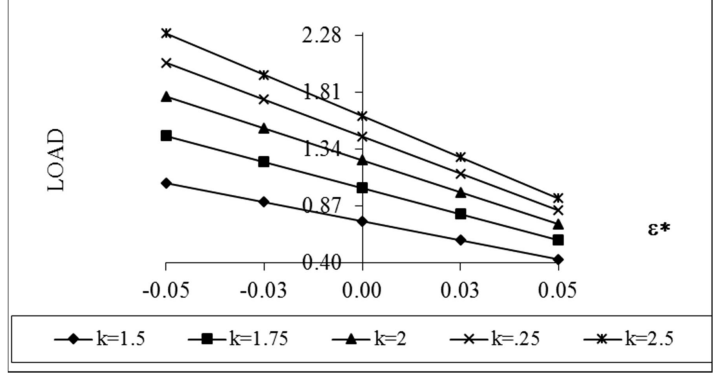

Figure 19: Profile of load bearing capacity with regards to $\varepsilon^{*}$ and $\mathbf{k}$

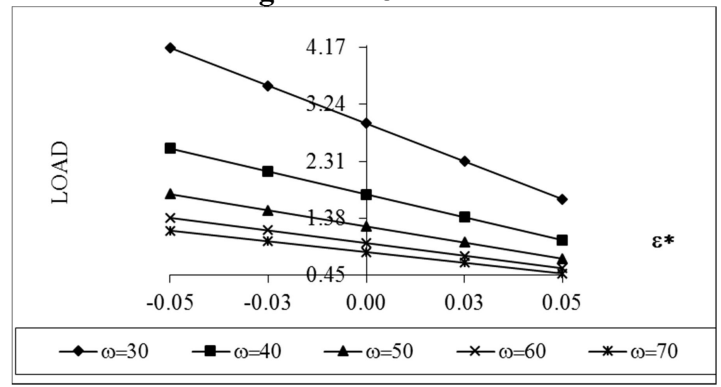

Figure 20: Profile of load bearing capacity with regards to $\varepsilon^{*}$ and $\omega$

While figures (19-20) shaws that the negatively skewed roughness augments the load as in the case of variance $(-$ ve). These trends reverse for positively skewed roughness and variance $(+\mathrm{ve})$.

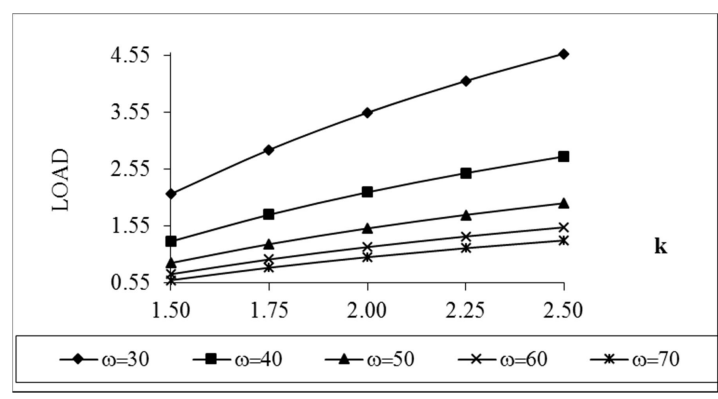

Figure 21: Distribution of load with respect to $k$ and $\omega$

The effect of $\mathrm{k}$ and $\omega$ is given in Figure (21), which makes it clear that the effect of the aspect ratio is significantly positive, while the load carrying capacity increases with increasing values of the semi-vertical angle.

\section{CONCLUSION}

The longitudinal roughness is easier to observe compared to the transverse roughness case. In fact, the standard deviation makes all the difference. Hence the roughness needs to be considered carefully while designing the bearing system. A close observation indicates that some amount of load is supported by the system even if no flow occurs. This does not happen in the case of traditional fluid based bearing system.

\section{REFERENCES}

[1] Andharia, P., Gupta J.L. and Dahari G. M. (1999) Effect of transverse surface roughness on the behavior of squeeze film in a spherical bearin, Proceedings of International Conference: Problem of Non-Conventional Bearing Systems NCBS'99, Journal of Applied Mechanics and Engineering, Special Issue, 4, p.p.19-24.

[2] Berthe D. and Godet M. A., (1973) A more general form of Reynolds' equation -application of rough surfaces. Wear, Vol. 27, p.p. 345-357.

[3] Christensen H. and Tonder, K. (1969a) Tribology of rough surfaces, Stochastic models of hydrodynamic lubrication. SINTEF, Section for Machine Dynamics in Tribology, Technical University of Norway, Trondheinm, NorwayReport No.10/69-18.

[4] Christensen H. and Tonder, K. (1969b). Tribology of rough surfaces, parametric study and comparison of lubrication models. SINTEF, Section for Machine Dynamics in Tribology, Technical University of Norway, Trondheinm, Norway, Report No.22/69-18.

[5] Christensen H. and Tonder K.(1970) The hydrodynamic lubrication of rough bearing surfaces of finite width. ASME-ASLE Lubrication conference Cincinnati, Ohio, October 12-15, Lub-7. [6] Davis M. G. (1963). The generation of pressure between rough lubricated, moving deformable surfaces. Lubrication of engineering, Vol.19, p.p 246-252.

[7] Dodge F. T, Osterle J. F. and Rouleau W. T. 


\section{Available online at www.ijrat.org}

(1965). Magnetohydrodynamic squeeze film bearings, Journal of Basic Engg. Trans. ASME, Vol. 87, p.p. 805-809.

[8] Elco R. A. and Huges. W. F. (1962). Magnetohydrodynamic pressurization in liquid metal lubrication, Wear, Vol. 5, p.p. 198-207.

[9] Guha S. K.(1993). Analysis of dynamic characteristics of hydrodynamic journal bearings with isotropic roughness effects", WEAR, Vol. 167, p.p.173 -179.

[10] Gupta J. L. and Dahari G. M. (1996.). Effect of roughness on the behaviour of squeeze film in a spherical bearing. Tribology Transactions, Vol. 39, p.p. 99-102.

[11] Kuzma D. C. (1964). Magnetohydrodynamic squeeze films, Journal of Basic Engineering. Transactions of ASME, Vol. 86, p.p.441-444.

[12] Kuzma D. C., Maki E. R., and Donnelly R. J. (1964).The magnetohydrodynamic squeeze films. Journal of Fluid Mechanics, Vol. 19, p.p.395-400.

[13] Patel K. C. and . Gupta J L. (1979). Behaviour of hydromagnetic squeeze film between porous plates. Wear, Vol. 56, p.p. 327-339.

[14] Patel K. C and Hingu. J. L. (1978). Hydromagnetic squeeze film behaviour in porous circular disks, Wear, Vol. 49, p.p. 239-246.

| [15] Patel R. M. and Dahari G. (2007). Magnetic fluid based squeeze film between porous conical plates. Industrial Lubrication and Tribology, Vol. 59(3), p.p. 143-147.

[16] Prajapati B. L. (1995). On certain theoretical studies in hydrodynamics and elastohydrodynamics lubrication, Dissertation, Ph. D. Thesis, S. P. University, V. V. Nagar.

[17] Prakash J. and Vij S. K.. (1973). Load capacity and time height relations for squeeze film between porous plates. Wear, Vol. 24, p.p.309-322.

[18] Shukla. B. (1965).Hydromagnetic theory of squeeze films, ASME, Vol. 87, p.142-144.

[19] Shukla, J.B. and Prasad R. (1965). Hydromagnetic squeeze films between two conducting surfaces. Journal of Basic engineering, Transactions of ASME, Vol. 87, p.p. 818-822.

[20] Sinha P. C. and Gupta J. L. (1974). Hydromagnetic squeeze films between porous annular disks, Journal of Mathematical and Physical Sciences, Vol. 8, p.p. 413-422.

[21] Ting L. L. (1975). Engagement behavior of lubricated porous annular disks part I: Squeeze film phase surface roughness and elastic deformation effects, Wear. Vol. 34, p.p.159-182.

[22] Tonder K. C. (1972). Surface distributed waviness and roughness. First World Conference in Industrial Tribology, New Delhi, A3 p.p.128.

[23] Zeng T. and Saibel E. (1967). Surface roughness effect on slider bearing lubrication, Journal of Lubrication Technology, Transactions of ASME, Vol. 10. p.p.334-338.
[24] Vadher P., Dahari G. and Patel R. M.(2008). Hydromagnetic squeeze film between conducting porous transversely rough triangular plates, Annals of Faculty of Engineering Hunedoara, 6, p. 155168.

[25] Andharia P. and Dahari G. (2001). Effect of longitudinal surface roughness on the behaviour of squeeze film in a spherical bearing. International Journal of Applied Mechanics and Engineering, 6(4), p.p. 885-897.

[26] Andhara P. and Dahari G. (2010). Longitudinal roughness effect on magnetic fluid based squeeze film between conical. Industrial Lubrication and Tribology, 62(5), p.p. 285-291.

[27] Andhara P. and Dahari G.. (2013). Performance of magnetic fluid-based squeeze film between longitudinally rough elliptical plates. ISRN Tribology, Article ID482604, 6 pages.

[28] Lin R., Lin M.C., Hung T.C. and Wang P.Y.(2013). Effects of fluid inertia forces on the squeeze film characteristics of conical plate's ferromagnetic fluid model. Lubrication science, Vol. 5(7), p.p. 429-439.

\section{NOMENCLATURE}

\begin{tabular}{|c|c|}
\hline $\mathrm{x}, \mathrm{y}$ & Cartesian coordinates \\
\hline $\mathrm{h}$ & Lubricant film thickness \\
\hline$\dot{\mathrm{h}}$ & Squeeze film velocity \\
\hline$\mu$ & Viscosity \\
\hline $\mathrm{B}_{0}$ & $\begin{array}{l}\text { Uniform transverse magnetic field applied } \\
\text { between the plates. }\end{array}$ \\
\hline $\mathrm{s}$ & Electrical conductivity of the lubricant \\
\hline M & $=\mathrm{B}_{0} \mathrm{~h}\left(\frac{\mathrm{s}}{\mu}\right)^{1 / 2}=$ Hartmann number \\
\hline $\mathrm{d}_{0}$ & Surface width of the lower plate \\
\hline $\mathrm{d}_{1}$ & Surface width of the upper plate \\
\hline $\mathrm{s}_{0}$ & Electrical conductivity of lower surface \\
\hline $\mathrm{s}_{1}$ & Electrical conductivity of upper surface \\
\hline$\phi_{0}(\mathrm{~h})$ & $\begin{array}{l}=\frac{\mathrm{s}_{0} \mathrm{~d}_{0}}{\mathrm{sh}}=\text { Electrical permeability of the } \\
\text { lower surface }\end{array}$ \\
\hline$\phi_{1}(\mathrm{~h})$ & $\begin{array}{l}=\frac{\mathrm{s}_{1} \mathrm{~d}_{1}}{\mathrm{sh}}=\text { Electrical permeability of the } \\
\text { upper surface }\end{array}$ \\
\hline$\omega$ & Semi vertical angle of the cone \\
\hline $\mathrm{p}$ & Lubricant pressure \\
\hline $\mathrm{W}$ & Load carrying capacity \\
\hline$\sigma^{*}$ & Non-dimensional standard deviation $(\sigma / \mathrm{h})$ \\
\hline$\alpha^{*}$ & Non-dimensional variance $(\alpha / \mathrm{h})$ \\
\hline
\end{tabular}


International Journal of Research in Advent Technology, Vol.7, No.3, March 2019

E-ISSN: 2321-9637

Available online at www.ijrat.org

\begin{tabular}{|c|l|}
\hline$\varepsilon^{*}$ & Non-dimensional skewness $\left(\varepsilon / h^{3}\right)$ \\
\hline $\mathrm{P}$ & Non-dimensional pressure \\
\hline $\mathrm{W}$ & Dimensionless load carrying capacity \\
\hline
\end{tabular}

